\title{
Discussion of the paper "A rational expectations model for simulation and policy evaluation of the Spanish economy"
}

\author{
Javier J. Pérez
}

Published online: 19 February 2010

(C) The Author(s) 2010. This article is published with open access at Springerlink.com

\section{Overview}

Rational expectations model for simulation (REMS) is a state-of-the-art Dynamic Stochastic General Equilibrium model (DSGE model) of the kind used in many policy institutions throughout the world. It shares a number of common features with standard models along this line of research, but also displays a number of specific features that makes it appealing for fiscal policy simulations. Indeed, among other particular features REMS encompasses: (i) a wider coverage of fiscal variables than in standard DSGE models, and (ii) a labour market specified along the lines of the "search" framework. While I think that the model is, in general, a relevant contribution to the literature, in my discussion I will hinge upon some weaknesses and problems with the modelling approach and the interpretation of the results that can be identified. For the sake of brevity I will focus on just a few points, grouped in two blocks. First, I will comment on non-standard features of REMS, as any critique to features standard in the relevant literature will make no justice to this particular model. Second, I will discuss some additional issues.

\section{Some comments on non-standard features of REMS}

The use of "rule-of-thumb" (RoT) consumers has become a standard characteristic of most recent DSGE model. Even though it represents a crude way of capturing

This commentary refers to the article available at: doi:10.1007/s13209-009-0013-8.

\footnotetext{
J. J. Pérez (ه)

Banco de España, Madrid, Spain

e-mail: javierperez@bde.es
} 
heterogeneity between households in the model, it is also true that it preserves tractability. Nevertheless, when modelling RoT consumers, REMS incorporates some specific features of RoT that may influence the results in a way that is difficult to ascertain ex-ante. First, in REMS RoT consumers do not hold money balances (as in, for example, Coenen et al. 2008), contrary to "Ricardian" consumers (in more general terms, one may wonder which is the role of money in REMS). Second, RoT consumers in REMS display lower steady-state consumption than "Ricardians", $70 \%$ according to the calibration provided in the paper (different from the $100 \%$ of Gali et al. 2007, for the US). This choice might have some implications for the interpretation of simulation results; in addition, and more importantly, the steady state ratio of aggregate consumption to total output will depend upon the fraction of rule-of-thumb consumers. The question is why do the authors need this last assumption, as equal steady state consumption can always be guaranteed by an appropriate choice of, for example, government transfers. Third, RoT consumers in REMS do not display habit in consumption, while "Ricardians" do. These specific features might be reasonable, but become odd when one realises that in REMS RoT consumers earn the same wage than "Ricardians" and push up wage negotiation on behalf of all (contrary to Coenen et al. 2008, with differentiated wages for differentiated labour services); RoT individuals put additional pressure on the average reservation wage as a way to ease their period by period constraint on consumption.

Thus, it is not clear what type of agents do the authors have in mind when modelling a somewhat extreme version of RoT consumers. If these are the poor, it may make more sense to compensate via government transfers the average lower level of consumption (lower steady-state consumption); but then, if they are the poor, it is not clear why the two types of workers should earn the same wage and negotiate wages in the same pool.

A second aspect is that it is difficult to assess, on the basis of the information provided in the paper, the gain of including the modelling of the labour market along the lines of the "search" paradigm. While the reasons usually called for in the literature are obvious, it is less clear in the framework of this very large model. In particular, given that the authors are forced to add an ad-hoc rule for wage smoothing, in such a way that wages are determined ex-post as a combination of the Nash-bargained wage and lagged wages.

\section{Other issues}

In such a large model, that puts so much attention to the government sector, one missing piece is the decomposition of government consumption into purchases of goods and services, and government wage expenditure. Given that the government is a relevant player in the Spanish labour market (it employs some $20 \%$ of the total working force) this seems like a relevant extension to make; alternatively, the authors could simplify other parts of the model in order to cover this issue. Modelling government wages and employment has been dealt with in the literature since the beginning of the 1990s, and most recently by Gomes (2009), along the lines of the "search" paradigm, and Fernández de Córdoba et al. (2009). 
A comment as regards the simulations shown in the paper: in response to a positive, transitory "government consumption shock", aggregate consumption increases on impact, due to the contribution of RoT consumers while the consumption of "Ricardians" fall. In this respect it would be interesting to see the reaction of hours worked by "Ricardians" and RoT consumers, as the standard increase in hours in the aggregate should also be coupled by a distinct behaviour of the two types of agents ("Ricardians" work more due to the standard wealth effect and wages follow, but what happens to the behaviour of RoT consumers in this respect?). In fact, it is not clear what happens to aggregate real wages, as the initial positive impact reverses very quickly, a fact that is quite puzzling.

Being an extremely ambitious and broad project, the development of REMS has been accompanied by the construction of a database for the Spanish economy. In relation to the fiscal block, the authors state that quarterly fiscal data have been fitted using a quadratic interpolation. But this approach is not appropriate to capture intra-annual dynamics in fiscal data. In addition, it disregards, in particular, two relevant pieces of information: (i) available quarterly data for the General Government sector; (ii) available monthly data for the Central government sector.

Finally, it is worth mentioning that it is not clear from the scarce evidence shown in the paper what stylised facts of the Spanish economy does the model capture. One misses some standard statistics that would show the ability of simulated data generated by the model, given the chosen calibration, to replicate some actual stylised facts of the Spanish economy.

Open Access This article is distributed under the terms of the Creative Commons Attribution Noncommercial License which permits any noncommercial use, distribution, and reproduction in any medium, provided the original author(s) and source are credited.

\section{References}

Boscá JE, Díaz A, Doménech R, Ferri J, Pérez E, Puch L (2010) A rational expectations model for simulation and policy evaluation of the Spanish economy. SERIEs 1:135-169

Coenen G, McAdam P, Straub R (2008) Tax reform and labour-market performance in the euro area: a simulation-based analysis using the New Area-Wide Model. J Econ Dyn Control 8:2543-2583

Fernández de Córdoba G, Pérez JJ, Torres JL (2009) Public and private sector wages interactions in a general equilibrium model, European Central Bank, Working paper, no. 1099

Galí J, López-Salido JD, Vallés J (2007) Understanding the effects of government spending on consumption. J Eur Econ Assoc 5:227-270

Gomes P (2009) Labour market effects of public sector employment and wages. London School of Economics, mimeo

Tagkalakis A (2008) The effects of fiscal policy on consumption in recessions and expansions. J Public Econ 92(5-6):1486-1508 